\title{
La presidencia de María Estela Martínez de Perón: la búsqueda de legitimidad y la descalificación del “otro" (1974-1976)
}

\section{The presidency of María Estela Martínez de Perón: the search of legitimacy and the disqualification of "the other" (1974-1976)}

\author{
María Celeste Napal \\ Universidad Nacional del Sur, Argentina. \\ celeste.napal@uns.edu.ar
}

Recibido: junio del 2016 Aceptado: septiembre del 2016

\section{Resumen}

El presente artículo busca analizar, a través de los discursos presidenciales, la imagen que la presidente María Estela Martínez de Perón (Isabel) construye del "otro" no partidario en un contexto político en el que se ve cuestionada su propia legitimidad. Partimos de la idea de que el período de su presidencia ( $1^{\circ}$ de julio de $1974-24$ de marzo de 1976) tuvo una identidad propia y que debió enfrentar una serie de desafíos derivados del vacío político generado por la desaparición del líder del movimiento peronista y de la creciente inestabilidad institucional que conducirá a su derrocamiento.

Palabras claves: discurso político; legitimidad; Peronismo; Década del '70.

\begin{abstract}
This article aims to analyze, through presidential speeches, the image that the president Maria Estela Martinez de Peron (Isabel) builds about the "other" - the political antagonist- in a context in where her own legitimacy was put into question. We start from the idea that the period of her presidency (1 July 1974- 24 March 1976) had its own identity and it faced a number of challenges from the political vacuum created by the disappearance of the leader of the Peronist movement and the growing institutional instability that will lead to her overthrow.
\end{abstract}

Keywords: political discourse; legitimacy; Peronism; 70s. 


\section{Introducción}

El tema del retorno del peronismo al poder tras el largo período de exilio, ha sido ampliamente estudiado.

A los efectos de introducirnos en el tema de nuestro interés, consideramos necesario hacer mención a algunas de las obras editadas que en los últimos años han analizado la etapa en cuestión, ya sea centrándose en ella específicamente o bien incluyéndola como parte de un proceso más amplio, marcado por el retorno del peronismo al gobierno.

En este sentido, podemos mencionar el caso de Los tres peronismos. Estado y poder económico, de Ricardo Sidicaro (2002). Allí el autor presenta el trienio 1973-1976, junto a la de los dos primeros gobiernos peronistas (1946-1955) y las presidencias de Carlos Menem (19891999), y lo aborda de manera general, sin distinguir la sucesión presidencial Cámpora-Perón-Ma. Estela Martínez de Perón. Sin embargo, su análisis nos permite visualizar las diferencias en los programas políticos desarrollados por los distintos gobiernos peronistas: durante los dos primeros (1946-1955) se privilegió la satisfacción de demandas de tipo económico y social de los sectores populares; mientras que en la segunda etapa (1973-1976) se intentó mantener ese lazo creado años antes en un contexto histórico completamente diferente, empleando para ello su instrumento principal: el Pacto Social. Durante el tercer gobierno (1989-1999), se produce un quiebre con estos sectores populares a través de prácticas que se desprenden de la connivencia del menemismo con los grupos económicos predominantes.

Por su parte, Alejandro Horowicz (1986) se concentra en la distinción de varias etapas al momento de analizar el fenómeno peronista. En este caso, el autor menciona cuatro peronismos: el primero, el de la inclusión obrera y la misión histórica; el segundo, el de la proscripción y la resistencia, que actuó como árbitro del juego político; el tercero, que comienza en 1973 y concluye con la muerte de Perón; y el cuarto, que nace a partir de la desaparición del líder, con la presidencia de María Estela Martínez de Perón, y se extiende hasta 1983, cuando el peronismo sufre una importante derrota electoral frente a Raúl Alfonsín. Este cuarto peronismo es considerado, por el autor, como el momento desarticulador del tercer gobierno peronista, donde se pondrán a prueba las posibilidades de un "peronismo sin Perón", en un sentido estricto.

Publicaciones más recientes, tales como las de Hugo Gambini (2008) y José Pablo Feinmann (2011), apuntan a escribir una historia integral del peronismo desde sus orígenes. Gambini, en su obra dividida en tres tomos, abarca un período de la historia que se extiende de 1943 a 1983; el último de ellos llamado Historia del Peronismo. La violencia (1956-1983) hace hincapié particularmente en los hechos de violencia perpetrados durante el exilio peronista, los gobiernos democráticos que forman parte del "retorno peronista", así como la radicalización durante la última dictadura militar. En tanto Feinmann, en su trabajo Peronismo. Filosofía política de una persistencia argentina Vol.2, se propone abordar el período abierto en 1972 con el primer 
retorno de Perón y cerrado con el golpe militar de 1976, haciendo una crítica al líder del movimiento desde su propia óptica, teniendo en cuenta que él mismo fue militante de la Juventud Peronista en la década de los 60'.

Sin embargo, pocos son los análisis que centran su atención puntualmente en el gobierno de María Estela Martínez de Perón (de aquí en adelante Isabel). En este sentido podemos mencionar las obras de Pablo Kandel y Mario Monteverde (1976), así como las de Julio González (2007) y Juan Bautista Yofre (2010) que focalizan su estudio en los momentos finales del gobierno peronista, desde la muerte de Perón hasta el golpe militar, concentrándose particularmente en el gobierno de su viuda y compañera de fórmula. Desde el enfoque biográfico, mencionamos las obras de Marcelo Larraquy (2007) y María Sáenz Quesada (2003). Respecto a los trabajos cuyo objetivo es resaltar el rol de las mujeres peronistas en la política, podemos mencionar las obras de Estela dos Santos (1983) y Jorge Halperin (2009). Mientras dos Santos realiza un análisis de la incorporación de las mujeres a la vida política vinculadas al partido Justicialista, Jorge Halperín hace hincapié en tres de sus figuras principales -Eva Duarte, María Estela Martínez de Perón y Cristina Fernández de Kirchner- comparando sus trayectorias profesionales, su experiencia política, la recepción que hizo la sociedad civil respecto de las posiciones políticas que cada una ocupó en la escena nacional.

Desde el punto de vista del análisis del discurso, podemos mencionar un artículo de reciente aparición de las autoras Alicia María Servetto y Melisa Paiaro (2012), que busca identificar en el discurso oficial de Isabel como presidente los argumentos que, según ellas, legitimaron los dispositivos de la violencia estatal y paraestatal como una manera para resolver los problemas sociales y políticos del país. En este sentido también se orienta la obra de Marina Franco (2012) quien presenta un nuevo enfoque respecto al tema de la violencia. La autora plantea la necesidad de relativizar el corte abrupto que se asigna al año 1976 como organizador absoluto de nuestra historia reciente, para ampliar el análisis a los años que van de 1973 a 1976, considerándolos un entramado de prácticas y discursos políticos que fueron constituyendo progresivamente una lógica político-represiva centrada en la eliminación del enemigo interno

Por otro lado, en materia de análisis del discurso peronista, pero referido concretamente al caso de los sectores de izquierda del movimiento, contamos entre otros con el clásico estudio realizado por Silvia Sigal y Eliseo Verón (1988) Perón o Muerte. En este libro, los autores abordan los discursos tanto de Perón como de la izquierda peronista. Desde un enfoque que permite interpretar el desconcierto que genera en estos sectores radicalizados la precandidatura a vicepresidente de María Estela Martínez de Perón.

Teniendo en cuenta esta bibliografía, desde luego no exhaustiva, resulta necesario reconocer que el período que nos interesa es analizado, en la mayoría de los casos, como una de las etapas más conflictivas a nivel político, social y económico de nuestro pasado reciente. Toma relevancia en tanto momento final de un tercer gobierno peronista que termina 
nuevamente con un golpe de estado y la instauración de un gobierno de facto que iba a extenderse hasta 1983. En consecuencia, consideramos que nuestro objeto de estudio sigue ofreciendo a la investigación histórica, múltiples aristas que hasta el momento no han recibido la suficiente atención y cuyo análisis contribuiría a dar una mayor profundidad y complejidad a su comprensión.

El trabajo tiene por objetivo poner de manifiesto las estrategias discursivas que emplea la presidente Isabel Perón para reforzar su legitimidad ${ }^{1}$ construyendo una imagen de "los otros", sus adversarios políticos, en el marco de una complicada situación política del movimiento tras el vacío de poder provocado por el fallecimiento del líder, Juan D. Perón. El fin último era el de generar consenso hacia su rol presidencial y advertir sobre cualquier posible disidencia ${ }^{2}$.

Respecto a las fuentes documentales, el tema se abordará a partir del análisis de los discursos oficiales de la presidente Isabel, a lo largo de su gobierno $1^{\circ}$ de julio de 1974 al 24 de marzo de $1976^{3}$.

Para analizar el discurso político ${ }^{4}$ de la presidente en el período en cuestión, partimos de las categorías empleadas por Eliseo Verón (1987, pp. 11-26). Este autor señala que en todo acto de enunciación política existen, a la vez, varios destinatarios. El enunciador político, al construirlos, entra en relación con ellos.

\footnotetext{
1 Existen distintas concepciones respecto al concepto de legitimidad, tomaremos aquella que distingue entre la legitimidad de origen y legitimidad del/por ejercicio. La primera (a veces sustituida por legalidad) tiene que ver sobre todo con la circunstancia de quien ejerce el poder y que éste lo haga en virtud de las reglas de un orden jurídico previo aceptado como vigente (en este caso, la Constitución Nacional). En tanto la legitimidad a propósito del ejercicio hace referencia al modo de ejercer el poder dentro de los límites y conforme a las pautas del orden normativo aceptado como vigente (lo contrario sería un ejercicio arbitrario del poder). Hablar de legitimidad por el ejercicio variante que tomaremos- nos lleva a enfocarla desde un punto de vista dinámico, como proceso de legitimación que no se ejerce en el vacío, ni sólo en relación a una masa de gobernados, indiferenciada y atomizada, sino en un espacio político en el que concurren otros actores, lo que lleva a distinguir entre actores legitimadores e impugnadores de la legitimidad. (Yoris-Villasana, 2004:94)

2 El aspecto vinculado con la autorrepresentación de Isabel Perón en su discurso político fue analizado en otro artículo de nuestra autoría denominado "Sólo soy la mano de Perón: La presidencia de María Estela Martínez de Perón, entre el liderazgo vacante y la construcción discursiva de la legitimidad (1974-1976)" en Revista PolHis, Año 7, Núm 13, enero-junio, 2014. Disponible en www.historiapolítica.com

${ }^{3}$ Los mismos fueron pronunciados con motivo de fiestas patrias, inauguraciones, actos partidarios (como el caso del 17 de octubre, Día de la lealtad peronista), anuncios respecto a problemas que involucran al país, así como comunicados referidos a obras de gobierno. La mayoría de los discursos que utilizamos, fueron editados por la Secretaría de Prensa y Difusión de la Nación, otros fueron recuperados de diarios de la época.

${ }^{4} \mathrm{Si}$ bien, el análisis del discurso en general y del discurso político en particular, no se agota en el análisis de los puntos que tendremos en cuenta a los efectos del presente trabajo, haremos hincapié en los discursos de Isabel y no las condiciones de recepción o de producción de los mismos. Noemí Goldman señala que dicho estudio implica tener en cuenta "...los entrecruzamientos de series textuales que constituyen objetos, enunciados, dispositivos y estrategias que remiten, de alguna manera, a contenidos ideológicos que producen efectos de sentido. Tener en cuenta las condiciones de emisión y los efectos de lectura de los textos, situar la producción y la circulación de los enunciados dentro de determinados espacios histórico discursivos..." (Golman, 1989, p. 21).
} 
El primero de ellos el prodestinatario, es el positivo, el partidario, aquel que se corresponde con el receptor que participa, adhiere y persigue las mismas, ideas, valores y objetivos del enunciador político. Por esta razón, el discurso político sirve a los efectos de reforzar el lazo con éste.

El destinatario negativo o contradestinatario, es aquel que se encuentra excluido del colectivo de identificación. Lo que es bueno, verdadero para uno es justamente lo inverso para el otro. La función del discurso político en este sentido apunta a generar polémica.

El autor nos indica que existe un tercer tipo de destinatario en el discurso político en un contexto democrático, se trata del paradestinatario, del indeciso, a quien se busca persuadir.

Estas categorías de análisis, que señalan múltiples destinatarios nos servirán para dilucidar, rescatar, no sólo lo enunciado explícitamente sino también lo implícito, lo que se expresa de manera solapada, especialmente en referencia a los aspectos persuasivos del discurso.

\section{Un poco de historia}

Con el regreso de Perón a la presidencia, la tarea de Isabel desde la vicepresidencia consistía principalmente en cumplir un rol institucional limitado a los actos de protocolo, ceremonias, recepciones, viajes al exterior como representante del gobierno argentino, así como tareas vinculadas a actividades de beneficencia (Sáenz Quesada, 2003: 135-138, 151-159). No obstante, el futuro le deparaba un protagonismo no esperado, al convertirse en presidente de la Nación.

Al acceder a la presidencia, Isabel Perón se enfrentó a múltiples problemas en el marco de un escenario complejo: la creciente confrontación con el sindicalismo, los sectores opositores dentro del propio Partido Peronista y el constante aumento de la injerencia de las Fuerzas Armadas en el ámbito político, resultado del papel que estaban desempeñando en la lucha contra la subversión ${ }^{5}$.

La política de Isabel se definió, como explica Liliana De Riz (1981), por el sectarismo y el aislamiento, antítesis de la estrategia de convergencia con que había regresado Perón en 1973, y terminó por alienarse uno a uno todos los soportes sociales.

La etapa que se abrió con la muerte de Perón quedó signada por la descomposición de la sociedad populista. La agudización de los conflictos y la intensidad de la violencia política fueron

\footnotetext{
${ }^{5}$ La escalada de violencia y la lucha que el gobierno mantenía con la guerrilla tuvo un foco de acción muy importante en la provincia de Tucumán hacia febrero de 1975 con el "Operativo Independencia" (Decreto $\left.N^{\circ} 262 / 1975\right)$. Excede los objetivos del presente trabajo el ahondar en la cuestión de la violencia ejercida durante el gobierno de María Estela Martínez de Perón, por esta razón y aunque no agotan el análisis del tema, recomendamos principalmente las obras de Marina Franco (2012); Oscar Anzorena (1998); Alicia Servetto (2010); Roffinelli y Artese (2005); Alicia Servetto y Melisa Paiaro (2012).
} 
el doble síntoma de la agonía. La singularidad de la coyuntura política creada por la muerte del jefe del peronismo se expuso en toda su dimensión por el hecho de que su desaparición dejaba a las distintas fuerzas sociales y políticas "no revolucionarias" ni golpistas, sin otra alternativa que la de apoyar la continuidad del proceso institucional (De Riz, 1981: 164-165).

Vemos que la situación se planteaba bajo la premisa: "Isabel o pérdida de la institucionalidad”. Como señala Liliana De Riz (1981):

Isabel significaba la continuidad institucional y condensaba en su figura al peronismo. En efecto, así lo entendieron los peronistas para quienes Isabel representaba el reaseguro de una unidad que, aunque precaria, los proveyera de un espacio de maniobra institucional dentro del cual dirimir sus pugnas internas. La tendencia revolucionaria temporalmente proclamó su apoyo a la viuda de Perón. El radicalismo lo entendió de la misma manera, en la esperanza de que su probada vocación democrática se viera recompensada con el éxito en las futuras elecciones que habrían de tener lugar a fines de 1976 (p. 165).

Las fuerzas armadas, por su parte, adoptaron una actitud de defensa de la institucionalidad a la espera de una salida política negociada o, en su defecto, de una intervención militar legitimada por el fracaso (Fraga, 1988).

\section{Representación de "los otros"}

Tal como señala Leonor Arfurch, el lugar del enunciador no se define solamente por la autorreferencia, sino también por ese "otro" que instaura ante sí, atribuyéndole determinadas competencias, saberes, expectativas (1987, p. 31). A ello podríamos agregarle la atribución de determinadas características que los identifican como "diferentes", "ajenos" y, por qué no, como opuestos y enemigos. Es a través de dichos rasgos que podremos identificar a quién se dirigen sus palabras en cada discurso y qué objetivos persigue al emplear determinadas expresiones.

Como señala Scandell Vidal, si convenimos en que la comunicación verbal es una actitud intencional dirigida a lograr determinado objetivo en relación con otras personas, resulta lógico pensar que el uso adecuado del lenguaje puede constituir un elemento determinante para el éxito del objetivo perseguido, más aún cuando estos objetivos pueden estar en conflicto con los de los destinatarios (1996, pp. 3-4).

El contexto de enunciación se modifica, pero también cambian los destinatarios del discurso. El enunciador político, al construirlos, entra en relación con ellos, las prácticas no se dieron en el vacío.

....al construir su destinatario positivo y su destinatario negativo, el enunciador entra en relación con ambos. El lazo con el primero reposa en la llamada creencia presupuesta. Es el receptor del discurso que participa de las mismas ideas, que adhiere a los mismos valores y persigue los mismos objetivos que el enunciador; es el prodestinatario. El destinatario negativo, está por fuera del colectivo de identificación y ello es justamente lo que lo define como tal (Verón 1989, p.17). 
Lo que hace la presidente es precisar las características que representan, a quienes adhieren a su figura dentro del gobierno y, por el otro, a "los otros". Para ello señala que de su lado están los resultados obtenidos a través de los distintos gobiernos peronistas en favor del pueblo. Del lado opuesto, están los mercenarios al servicio de intereses ajenos a los nacionales, aquellos que se aprovechan de los frutos del esfuerzo de los "verdaderos trabajadores" y atacan a su gobierno. Estos enemigos se venden al mejor postor, se valen de la violencia como forma de acción -que asocia a la utilización de drogas-, esparcen rumores con el objetivo de dañar al gobierno y de obstaculizar su tarea. En este sentido Isabel (1974e) señala:

Todo el pueblo sabe muy bien quién es el enemigo. De nuestro lado está la firmeza lograda en años de lucha, la claridad de la doctrina Perón, el sacrificio de amor de Eva Perón, la esperanza y la fe de todo un pueblo. De nuestro lado está la Patria. (...) De nuestro lado están los símbolos patrios (...) por encima de la pequeñez de quienes, con violencia, drogas, perjurio o prebendas, entregan al enemigo foráneo los valores que sus progenitores conquistaron con sacrificio durante una larga vida de trabajo. Además de la violencia y el asesinato cobarde y mercenario, existe una enorme cantidad de rumores que se esparcen (...) Se ataca a los hombres del Gobierno que más trabajan por la felicidad y prosperidad de la Nación, creyendo que el pueblo puede engañarse. (p.74)

No nos puede molestar esa mala información que se produce porque hay intereses deseosos de que el gobierno no camine, no realice ni continúe haciendo lo que debe a favor de nuestro pueblo. Repito, eso no nos debe desanimar. (p. 77)

No quiero hacer nombres pero ustedes [los gobernadores] son lo suficientemente inteligentes para saber a quiénes van dirigidas mis palabras (p.82)

La presidente no tiene necesidad de nombrar a los enemigos porque entiende que el pueblo ya los conoce. Si la acción de nombrarlos permite identificarlos, el no hacerlo les quita identidad. El enfrentamiento es evidente, no así el enemigo que se vuelve difuso. Nadie puede estar seguro de a quien se dirigen sus palabras, cualquiera es susceptible de ser catalogado como contrario. Existe una intención por dar cuenta de que ella conoce a sus enemigos, pero el hecho de no exponerlos públicamente podría ser interpretado como una estrategia para no enfrentarlos directamente o para poder modificar "este colectivo" según las circunstancias.

\section{La traición}

Desde el momento en que Isabel comienza a desempeñar una función política -en primer término, en calidad de vicepresidente- una de sus mayores preocupaciones se vincula a su deseo por desenmascarar a aquellos falsos peronistas que intentan separarse del camino iniciado por el General Perón. Dirigiéndose exclusivamente a sus compañeros peronistas al usar un nosotros inclusivo, Isabel (1974a) señala:

Conocemos bien que existen muchos compañeros dirigentes, que han olvidado todo cuanto dice nuestra Doctrina Justicialista. Conocemos bien que su camino será muy corto 
y qué baldón de traidor iluminará su camino en la Historia futura. Conocemos bien que las pasiones, las vanidades engendran ambiciones desmedidas y que muchos se apartan de los enunciados y quieren obrar por cuenta propia, careciendo de los valores necesarios para conducir a los hombres con la verdad como pendón... (p. 6)

... comprendemos que el hombre que trabaja peronísticamente en cualquier sector, merece el respeto y la consideración de sus compañeros, pero aquel que olvida estos principios se ubica en terrenos cercanos a la traición, apartándose del cuerpo madre del MOVIMIENTO, o bien aislándose en grupos sectarios bajo caudillos interesados o al servicio de elementos extraños a nuestra nacionalidad, se exponen a ser juzgados con toda severidad por las bases y a ser apartados definitivamente del MOVIMIENTO, como si fueran atacados de un terrible mal contagioso... ¡LA TRAICION! (p.19) ${ }^{6}$

Nuestro MOVIMIENTO no detiene a nadie por la fuerza. O se está íntegramente con él o se ubica a la persona en la acera de enfrente, pero actuando entonces con sus valores propios y no utilizando mas la camiseta peronista... (pp. 15-16)

La presidente habla de traición, pero en estos pasajes, la misma se restringe al ámbito interno del movimiento.

La intención de Isabel es la de dejar claro que sólo hay y puede haber un conductor, un líder, el primero es Perón. Como señala Martín Rojo, los discursos no reflejan la realidad, sino que construyen, mantienen, refuerzan interpretaciones de esa realidad. Al mismo tiempo entiende que existe un principio de desigualdad respecto a los discursos que explica por qué algunos discursos están autorizados, legitimados frente a otros des-autorizados, des-legitimados (Martín Rojo, 1996, pp. 2-3). El discurso del líder, es el discurso legitimado, sus preceptos e ideas son las que pueden contribuir a sostener un mínimo de cohesión en el movimiento, en un momento en que todo parecía desmoronarse. Ella en su calidad de continuadora, también gozaría de esa legitimidad.

Sus expresiones se constituyen en un llamado a respetar la verticalidad del movimiento. El alejamiento en que pueda incurrir cualquier persona o grupo respecto de los principios básicos de la doctrina peronista, es entendido en términos de traición. El disenso no está permitido y la separación en grupos, que aún perteneciendo al movimiento, respondan a cualquier otro líder que no sea Perón, serán castigados. Estos grupos sectarios son comparados con una enfermedad, definidos como un terrible mal contagioso y, por lo tanto, serán apartados. El recurso a realizar analogías de tipo biologisista, como comparar la Nación con un organismo vivo, así como agentes disidentes de intereses contrarios a los propios con enfermedades, será un elemento que se reiterará a lo largo de su gobierno. Por ejemplo, en el acto de celebración del Día del Trabajador, en mayo de 1975, Isabel (1975a) expresa:

Aquello que está débilmente estructurado, se destruye con suma facilidad, sobre todo si la influencia que predomina, atiende solamente a los intereses sectorizados. Esa es la grieta por la cual el precioso contenido común se derrama, y por donde penetran los agentes que disocian y paralizan, provocando la enfermedad en el organismo nacional. (p. 7)

\footnotetext{
${ }^{6}$ Las mayúsculas son originales.
} 
De este modo, podemos observar que los traidores no son sólo aquellos que no respetan la jerarquía de mando interna del partido, también lo son quienes persiguiendo objetivos propios trabajan al servicio de ideologías extrañas, por ello entendemos ideologías distintas a la justicialista. En este sentido Isabel (1974a) agrega:

Los que se aprestan a funcionar al servicio del imperialismo, cualquiera sea su doctrina, dejan de formar parte del PUEBLO para ingresar en las filas indignas de la traición. (p. 28)

Las palabras de la presidente ponen en un primer plano la importancia del par lealtadtraición, valores contrapuestos que se ponen en juego en los fragmentos que venimos analizando. Ambos resultan las dos caras de una misma moneda, en tanto no dan lugar a una tercera opción: Isabel no deja lugar a la indefinición, se es leal o traidor.

Quienes también son considerados traidores son los acaparadores, señalados por Isabel como los responsables de la especulación que provocaría los problemas económicos que se presentan en su gobierno.

Al culparlos de la situación de desabastecimiento, los coloca en el lugar de enemigos de la Patria, promotores del temor entre los compatriotas. En otras palabras, desde su óptica, el enemigo no limita su accionar al interior del movimiento, sino que afecta a todos los argentinos:

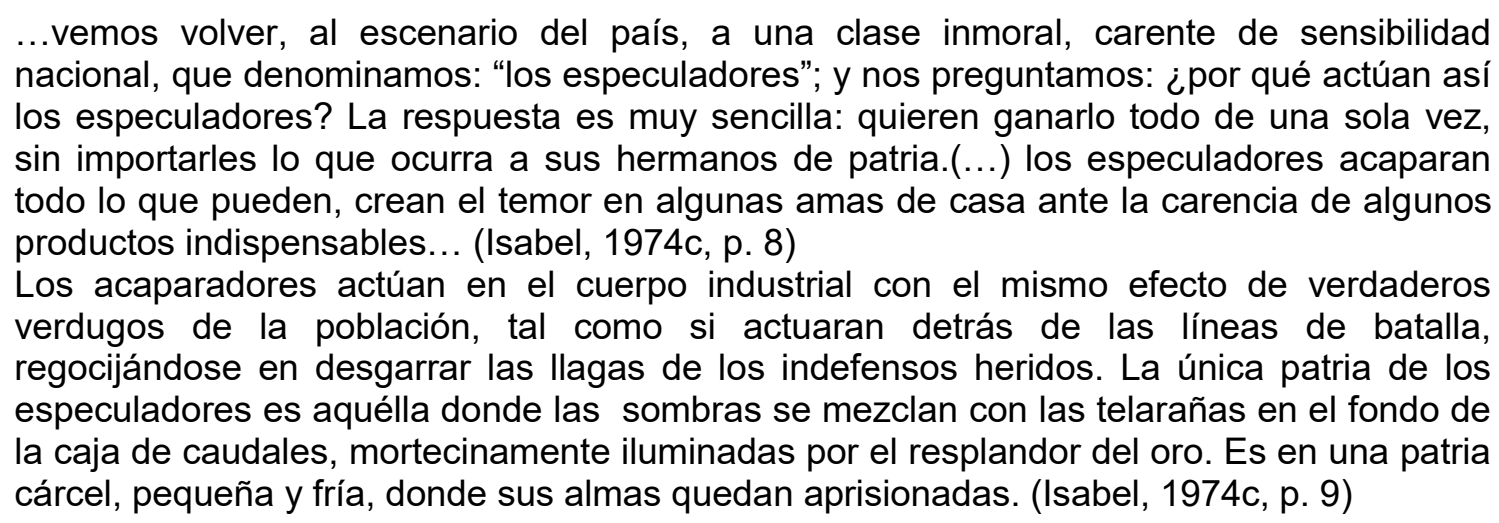

La presidente no duda en equiparar a los acaparadores nuevamente a una enfermedad como el cáncer, que amenaza con invadir los hogares argentinos:

De continuar cometiendo estos delitos, pueden tener la plena seguridad de que se tomarán medidas muy severas, para terminar definitivamente con el incipiente cáncer que amenaza introducirse en los hogares argentinos. (Isabel, 1974c, pp. 13-14)

El combate frente a los enemigos de la Patria sería librado, en ese momento, teniendo en cuenta lo que la justicia determine, será ésta la que dará el veredicto final. Se respetarán los derechos civiles de los acusados, el castigo se proporcionará de acuerdo a lo establecido por la ley.

Quede bien claro que esta especulación destructora del salario real será implacablemente perseguida por el gobierno y por el pueblo en todas sus formas y magnitudes. No habrá 
compasión sino implacable justicia, ya sea para la gran empresa monopólica cuanto como para el vendedor domiciliario que falsifique calidades o reclame precios exorbitantes... (Isabel, 1976b S/R)

Si bien el problema de la especulación, adquiere mucha relevancia en un contexto de crisis económica como el que se vivía en ese momento, se trata de un problema puntual. La acción de los acaparadores está identificada y la actitud de aquellos frente al pueblo argentino, habilitaría al gobierno para tomar las medidas necesarias con el objetivo de poner fin a su acción destructora. Como veremos, el problema que comienza a tomar aún más relevancia es el de la violencia y sus palabras se dirigirán a identificar y caracterizar a los promotores de este accionar violento, entre los cuales los jóvenes ocuparían un lugar central.

\section{La juventud descontrolada}

Es a estos jóvenes a quienes adjudica -incurriendo en el consumo de drogas y el uso de la violencia- el haber subvertido el rumbo que todo argentino debe llevar, el orden social y moral, interfiriendo en el desarrollo nacional. Cualquier acción en este sentido se convierte en antiargentina.

En la $59^{\circ}$ reunión de la Organización Internacional del Trabajo, en julio de 1974, Isabel se expresa en los siguientes términos:

Se hace evidente que un plan destructivo está en plena ejecución. Se observa desesperación por lograr el poder. Se vislumbran estados de incertidumbre en una humanidad que se debate en la orfandad de su carencia de principios morales y que no conoce su destino final. Y dentro de esa muchedumbre, la juventud descontrolada que rompe los lazos de convivencia para ingresar en una guerra revolucionaria, que no siempre tiene objetivos dignos de tal sacrificio. Son jóvenes que sienten dentro de sí una angustia interior, que los lleva a descargar su vitalidad en "algo" que no comprenden bien (Isabel, 1974b, p. 17).

Sabemos que [los empresarios] están siendo objeto de la subversión, cuyo objetivo es paralizar la producción y la industria nacional. La Reunión de Gobernadores ha servido para que hablemos claro sobre la forma de terminar con esta acción antiargentina y (...) para que el desarrollo y la seguridad nacional, no sean interferidos por la acción de las minorías extremistas de derecha o izquierda (Isabel, 1974e, p. 90).

Como podemos observar en las últimas citas, Isabel hace un diagnóstico de la situación que le toca enfrentar a poco de comenzar su gobierno, para luego identificar a un grupo en concreto. Dentro de esa muchedumbre, la presidente hace foco en la juventud descontrolada. Éstos jóvenes angustiados, no están en condiciones de entender el error en el que se implican al unirse a la guerra revolucionaria. Si bien parece que, por un lado los excusa de las consecuencias de sus actos en virtud de su propia juventud y de su angustia interior, al mismo tiempo los desautoriza en tanto asegura que se están involucrando en algo que no comprenden bien. 
Estos jóvenes habrían llegado a establecer cierto grado de organización formando un frente terrorista contra el gobierno. Éste deberá enfrentarse a él a través de la acción de las Fuerzas Armadas:

... existe un frente terrorista, ateo, mercenario, inhumano y delirante, empeñado en trastocar nuestros principios y valores más esenciales, regando con sangre inocente nuestro suelo patrio. Esta es la realidad subversiva en la que tendréis que desarrollar [jóvenes oficiales] vuestra acción (Isabel, 1976a) ${ }^{7}$

En la cita precedente, Isabel, realiza una diferenciación respecto a los jóvenes separando a quienes componen ese frente terrorista, ateo, mercenario, inhumano y delirante, de quienes tendrán la tarea de enfrentarlos, los jóvenes oficiales de las Fuerzas Armadas. Estos jóvenes oficiales, representarían las características opuestas: cristianos, al servicio de la Patria, humanos y racionales.

La presidente denuncia que el fin último de la subversión es derrocar al gobierno peronista, ello justificaría la acción del estado para corregir la situación. Es esta acción violenta la que, desde su punto de vista, pone en jaque los principios democráticos:

El terrorismo y los asesinatos fríamente encauzados contra figuras destacadas de la vida nacional, o los arteros ataques contra los integrantes de las Fuerzas Armadas, tienden a la anulación de toda libre expresión de la democracia, que nuestras mejores tradiciones han marcado como rumbo fundamental en la vida del país. (Isabel, 1974f, p. 11)

Los jóvenes no eran más que, en última instancia, instrumentos del verdadero enemigo que la presidente asocia a las "ideologías extrañas" cuyo interés reside en derrumbar la obra de gobierno peronista. Estas fuerzas promueven el caos:

Las premisas sociales y existenciales que conformaban la seguridad de nuestros padres ya no existen. Además hay peligros más sutiles que los mencionados, que se infiltran dentro del hombre mismo a través de la contaminación ideológica, del imperialismo de la cultura y de todos los fanatismos. Son fuerzas desintegrantes que van socavando la confianza del hombre en sí mismo, y que proceden no sólo de afuera sino de nuestro propio ser. (Isabel, 1974e, p. 7)

El gobierno no desconoce el problema al que se enfrenta y, manteniéndose sereno pero vigilante, busca "adaptar" a quienes se han apartado de la sociedad.

Nuestro gobierno popular ha mantenido su espíritu sereno y sus sentidos vigilantes, aplicando las medidas necesarias para tratar de encauzar a los seres inadaptados de nuestra sociedad... (Isabel'1974f, p. 11)

\footnotetext{
${ }^{7}$ María Estela Martínez de Perón, "Discurso de Isabel Perón en el Teatro Colón el 1 de enero de 1976 con motivo de la entrega de sables y espadas a los nuevos oficiales de las FF.AA", Diario La Nación 10 de enero de 1976 en Itcovitz Victoria "Estilo de gobierno y crisis política (1973-1976)", Centro editor de América Latina, Buenos Aires, 1985, p. 131.
} 
Su gobierno habría intentado calmar las pasiones que guían el accionar de los jóvenes, pero Isabel admite su fracaso en ese aspecto ya que la violencia continuó creciendo. La juventud debe ser adaptada, ajustada, encarrilada dado que han perdido el rumbo. La presidente asocia la acción revolucionaria de los jóvenes a la utilización de drogas en lugar de vincularlo a la firme convicción de estar luchando por una causa en la que creen. Por ello; no dota a la juventud de capacidad de discernimiento entre lo que está bien y lo que está mal.

Se buscó encarrilar las pasiones por todos los medios y mucho se logró en el ámbito de la juventud. Pero el tiempo transcurrió y la violencia no amainó. Muchos inadaptados ingresaron en el mundo caótico de la alucinación y de las drogas, renegando de todo aquello que significara orden y progreso. (Isabel'1974f, p. 11)

Nadie que medite con seriedad y con desapasionamiento, podrá dejar de percibir, que las armas que asesinan tienen unas manos que aprietan el gatillo con la frialdad e insensibilidad, que un cerebro "lavado", un bolsillo cargado, una conciencia amedrentada y una cantidad de "drogas en su organismo", ejecutan; tienen mentes puramente materializadas que participan en el Gran Anticristo que las Sagradas Escrituras nos indican desde siglos. Perón los denominaba como la gran sinarquía internacional y tenía razón. (Isabel 1975a, p. 11)

Inhabilita a los jóvenes como actores políticos e interlocutores válidos porque usan drogas, son inadaptados, reniegan de los valores cristianos, son asesinos, fríos e insensibles.

Una de las causas a las que atribuye el accionar subversivo de los jóvenes a la crítica situación por la que atraviesa la educación:

El área de la educación fue recibida por nosotros en un febril estado de descomposición, donde la inoperancia y el descuido facilitaron el desorden y la anarquía, terreno fácil para el nacimiento de los vicios. Colegios y Universidades perdieron la tradicional alegría del estudiantado para convertirse en refugio anárquico de la violencia y de la subversión. (Isabel 1975a, p. 13)

El estado de descomposición en el que ella afirma se encontraba la educación, a la que califica de inoperante, descuidada, promotora del desorden, la anarquía y los vicios, le brinda, desde su punto de vista, las razones suficientes para justificar la intervención de algunas instituciones de educación superior como la Universidad de Buenos Aires (Saénz Quesada, 2003, pp. 184-186). La grave situación educativa era un problema de colectivo, por ello la presidente señala:

El desencanto de la no-realización, que padecen muchos jóvenes del presente, es el resultado de siglos de guerras militares, económicas, sociales, psicológicas y laborales, donde constantes presiones y estados familiares de permanente angustia, han sembrado la anulación de la fe. (...) Es en el período de la vida estudiantil, cuando el alma comienza a exteriorizarse, junto con su capacidad receptiva. Ese es el momento de estudiar sus inclinaciones y guiarlos por senderos de grandeza, con visión de futuro, respetando a los demás, para poder respetarse a sí mismos. Cada maestro y cada padre de familia, debe revisar sus propias normas de conducta y de vida. La trayectoria de un ser nacido de su sangre o de su sabiduría, es algo tan valioso. Que perderlo en las sombras del vicio, la 
violencia o la soledad en medio de la multitud, es grave ofensa a los derechos humanos. (Isabel 1974e, p. 71)

Como vemos en párrafo precedente, Isabel busca tomar distancia de la situación que dio origen a la problemática que le toca enfrentar en ese momento, atribuyéndola a una sucesión de hechos de distinto orden con los cuales su gobierno no se ve relacionado. Desde su mirada, es una tarea que involucra a las familias y a los profesores encargados de formar afectiva e intelectualmente a los jóvenes. Lo que Isabel intenta es sumar a padres y docentes a su "cruzada" contra la violencia.

\section{En busca de la solución a la violencia}

Su función como presidente es la de alertar al pueblo sobre los peligros que se ciernen sobre la Nación y, al mismo tiempo, los convoca a luchar contra el caos porque la alternativa a la lucha es la dominación:

En mi tránsito por las provincias del país quiero alertar a sus habitantes sobre la infiltración de mercenarios al servicio de intereses foráneos que buscan con la infamia, la violencia y la amedrentación de los humildes que entreguemos el país al caos, permitiendo que el enemigo oculto se enseñoree de la Nación para convertirla en esclava y dominarla. ${ }^{8}$

Como forma de ilustrar la situación en la que se encuentra el país, Isabel elabora una analogía entre el corazón humano con sus aurículas y ventrículos derecho e izquierdo -en tanto órgano vital- y la división entre las posturas políticas asumidas por distintos grupos, para sostener la necesidad de encontrar un punto medio entre ambos extremos para que el cuerpo social funcione correctamente:

El órgano cordial se compone, evidentemente, de una unidad formada por dos corazones, al igual que lo vive también nuestra propia Nación. Dentro de la unidad tiene el corazón humano, estrechamente ligado para una supervivencia total, a un corazón derecho compuesto de la aurícula y el ventrículo derecho, y a un corazón izquierdo compuesto por la aurícula y el ventrículo izquierdo. Con esas dos facetas de un mismo todo, el órgano humano funciona como una bomba aspirante e impelente, cuya energía es proporcionada por la contracción del propio músculo cardíaco. La Nación sus derechas y sus izquierdas que, actuando en diferentes intensidades, desde la oposición literaria a la violencia incontrolada, olvidan la necesidad imperiosa de poder subsistir viendo en la Tercera Posición, aquella donde el centro unificador que posee acumula y recibe la energía del pueblo, consolidada en una posición netamente patriótica, actúa como el músculo cardíaco de la Nación, equilibrando exactamente el correcto fluido del precioso líquido vital que permitirá a su pueblo una larga vida, sana y feliz. (Isabel 1974e, pp. 97-98)

\footnotetext{
${ }^{8}$ Diario La Nueva Provincia, "Visita el interior la jefa de estado", Bahía Blanca, 13 de Octubre de 1974, p 3, cols 3-6, continuación p 5, col. 1.
} 
Lo que destacamos de éste último fragmento es la hábil utilización que Isabel hace de la metáfora para poner de manifiesto la centralidad que otorga a la doctrina de la Tercera Posición, como punto medio, como centro unificador, sinónimo de Patria, como corazón de la Nación del cual depende que el pueblo alcance una larga vida, sana y feliz. Al dotar a dicha doctrina de las características antes mencionadas, dificulta la opción por cualquier otra postura, ya sea la izquierda -violencia incontrolada- o la derecha -oposición literaria-.

Isabel se muestra desconcertada frente a la posibilidad de que un argentino se enfrente a otro compatriota. Atribuye nuevamente esta conducta violenta, el caos reinante, al desencanto y la injerencia de ideologías extrañas que no hacen más que perturbar el orden social que ella, como gobernante busca mantener:

No puedo suponer que un argentino se ponga en la acera de enfrente para combatir a otro argentino por un interés personal o por ideas extrañas a nuestro ser. Tampoco es posible que un argentino esgrima un arma para matar a otro argentino" (Isabel, 1974f, p. 15)

La presidente interpela a este colectivo de personas que denominamos "los otros", con el objetivo de pedirles que depongan las armas, cesen con los actos violentos y retornen a la senda establecida por el gobierno, el camino del bien.

...ruego para que las pasiones incontroladas retornen al cause positivo del trabajo patriótico... (Isabel, 1974f, p. 13) ${ }^{9}$

Se nos hace evidente que el gobierno busca reanudar el diálogo respecto a un tema que considera de interés nacional. También podemos entender esta convocatoria, como una estrategia para delegar en otros una responsabilidad que, como primer mandataria le corresponde, es decir, el peso de encontrar solución al tema de la violencia acuciante.

Si bien Isabel se muestra interesada por conocer las posturas de los partidos opositores y por la ayuda que puedan brindar los ciudadanos comunes desde el seno de la familia o desde las instituciones educativas, busca dejar claro que es el gobierno quien tiene la capacidad y el poder para erradicar toda expresión de terrorismo y subversión. En un discurso titulado "El país contra la violencia", la presidente señala:

Prosiguiendo el diálogo iniciado por el Teniente General Perón, (...) he querido convocar a las fuerzas activas del país, a fin de intercambiar opiniones sobre la necesidad de erradicar definitivamente del ámbito nacional, toda expresión de terrorismo y subversión. (Isabel, 1974f, p. 9)

He querido traer este tema de la subversión porque, evidentemente, el gobierno tiene en sus manos el poder de erradicar totalmente la violencia del país (Isabel, 1974f, p. 14)

\footnotetext{
${ }^{9}$ Discursivamente les está "dando una oportunidad" de poner fin a la violencia, sin embargo, ISABEL parece no albergar demasiadas esperanzas en que ello suceda de manera voluntaria, razón por la que la presidente se reúne con representantes de las distintas fuerzas políticas a fin de encontrar entre todos una solución a este problema, lo que nos habla de un colectivo de personas que excede a los meros partidarios.
} 
Lo que resulta significativo es el verbo que Isabel utiliza en su discurso. Erradicar significa arrancar de raíz, lo que la presidente no explicita son los medios que utilizará para ello. Es evidente, teniendo en cuenta sus palabras, que la violencia no será descartada como modalidad de acción gubernamental:

[Es] un deber inexcusable de todo argentino, la lucha contra la subversión, la violencia y el terrorismo. Esta lucha debe ser sin distingos de ninguna clase (...) y con un solo fin, que es erradicar la reacción terrorista definitivamente, y a todos aquellos que se quieren encaramar en el poder, usando la camiseta peronista. La subversión ataca (...) al gobierno peronista, al que quiere desalojar del poder. Pretende también provocar una subversión sediciosa desde arriba para luchar así, en un mismo terreno de ilegitimidad, porque aquí, el único heredero es el pueblo. (...) No dejaremos sector sin atacar y corregir. Afrontaremos nuestra responsabilidad, sin titubeos ni declinaciones. (Isabel, 1975b, p.7) Si vemos que la violencia llega ya hasta el seno de los hogares familiares, donde se producen secuestros y asesinatos que nadie sabe ya a qué atribuir, tal es el caos reinante, es lógico comprobar que están descartados violentamente el espíritu del diálogo y de la comprensión; viendo avanzar a pasos agigantados el dominio y la ingerencia [sic] foránea dentro del país, con sus consecuencias a la vista... (Isabel, 1974ª , p. 49)

Si quedan descartados el diálogo y la comprensión, la única alternativa viable es la violencia.

En todo momento la gobernante aclara a partidarios y enemigos, empleando incluso expresiones que podrían interpretarse como una amenaza - pese a quien pese y caiga quien caiga-, que no permanecerá indiferente a los ataques. Su intención es defender la felicidad del pueblo frente a cualquier peligro.

...tengan la plena seguridad que estaré siempre firme, pese a quien pese y caiga quien caiga, para salvar al pueblo argentino. ${ }^{10}$

[A los trabajadores]...les digo: "Tengan fe; tengan confianza, porque yo los llevaré, pese a quien pese y caiga quien caiga, a la felicidad que este pueblo maravilloso merece" (Isabel $1975^{\mathrm{a}}$, p. 17).

Desde nuestro punto de vista, la presidente va a construir desde lo discursivo una serie de argumentos que le permitan justificar actos violentos usando el aparato represivo del estado, cuando de ello dependa la seguridad y el bienestar del pueblo todo. En este sentido, recurre a la utilización de citas de autoridad de personajes políticos y referentes filosóficos y religiosos, unidos a ejemplos concretos de otras sociedades que han atravesado los mismos conflictos:

EUROPA que lleva muchos años de civilización y ha atravesado por todos los caminos de la experiencia tiene sobre estos temas [referidos a combatir la violencia] conceptos dignos de estudiar (...) Por ejemplo, dice JOSÉ ANTONIO PRIMO DE RIVERA: "La violencia no es censurable sistemáticamente. Lo es cuando se emplea contra la Justicia". Pero hasta SANTO TOMAS, en casos extremos, admitía la rebelión contra el tirano. Así, pues, el usar la violencia contra una secta, triunfante, sembradora de la discordia, negadora de la

\footnotetext{
${ }^{10}$ Diario La Nueva Provincia, "Nuevo mensaje presidencial", Bahía Blanca, 14 de Octubre de 1974, p. 4, cols 1-4.
} 
continuidad nacional y obedientes a consignas extrañas... ¿por qué va a descalificar el sistema que esa violencia implante? (Isabel, 1974ª, p. 51)

Su postura se endurece, el límite queda marcado, existe una progresión que va de la sorpresa a la justificación y de ella a la acción que la llevará a implementar un plan de represión que, antes que frenar el accionar violento, lo profundiza.

Tal como si se tratara de una premonición la por aquel entonces todavía vicepresidente María Estela Martínez de Perón, señalaba en junio de 1974:

...los argentinos, ¿hemos cumplido con Perón? Los hechos reales, los encabezamientos de los periódicos, la violencia de unos inadaptados mercenarios, los rumores que favorecen el trabajo del enemigo foráneo, demuestran que los argentinos se quedan en una posición negativa, dejando que el mal avance sin ponerle remedio a tiempo. (Isabel, 1974c, p. 12)

Esas palabras que expresa a modo de balance se presentan con una vigencia sorprendente, cobran significativa importancia hacia el final de su gobierno, en tanto aquellos problemas enumerados, continuaban sin solución.

\section{Palabras finales}

Con el regreso del peronismo al poder en 1973, María Estela Martínez de Perón comenzó a ocupar un papel destacado y activo en la vida pública de nuestro país. Su lugar de esposa y persona de confianza del General Perón durante su exilio, le permitió ocupar el rol de compañera de fórmula presidencial, acompañando a su esposo. Las elecciones celebradas en 1973, tras las renuncias de Héctor Cámpora y su vicepresidente Vicente Solano Lima, dieron como resultado una abrumadora victoria de la dupla Perón-Perón. Entendemos que dicha victoria -con el $62 \%$ de los votos- dotó a Isabel de un status de legalidad y legitimidad para desempeñarse como vicepresidente de la Nación.

La muerte de Perón lleva a su esposa a asumir la primera magistratura, de acuerdo a como lo establece la Constitución Nacional. El "equilibro" se rompe al fallecer el líder del Movimiento, ya que si bien la presidencia de Isabel es legal en tanto así lo establece la ley, es su legitimidad para ocupar el Poder Ejecutivo Nacional, la que es puesta en cuestión. Isabel contaba con una legitimidad de origen, al ser elegida por el pueblo en elecciones libres, pero no así con una legitimidad por el ejercicio, situación que la llevará a desplegar una serie de estrategias discursivas con el objetivo de legitimarse en el cargo que le toca ocupar. En ese proceso, Isabel construye una imagen del partidario (prodestinatario) que no puede separarse del "otro enemigo" (contradestinatario).

El primero es definido a través de un "nosotros", colectivo de identificación sinónimo de Patria que cuenta con ciertas características positivas que hacen referencia a valores que se busca resaltar: son leales, trabajadores, cristianos, verdaderos patriotas, racionales, al servicio 
del orden y del progreso de la Nación. Si bien este "nosotros" no fue analizado en el artículo, vale destacarlo dado que se contraponen a la figura del "otro".

El enemigo, queda excluido de dicho colectivo, razón por la que se les adjudica una serie de características negativas. Los "otros" son la antipatria, traidores, violentos, mercenarios al servicio de intereses foráneos, inadaptados, drogadictos, ateos, sinónimos de enfermedad, inhumanos, delirantes, insensibles, fríos. Este grupo no limita su accionar destructivo, a los límites del propio partido sino que se extiende a la sociedad en su conjunto. Es decir, se convierten en un problema, ya no partidario, sino social, cuya solución recae en todos los habitantes del país.

La representación que la presidente realiza de aquellos que constituyen el "nosotros" y "los otros" se basa en una concepción dicotómica que, en líneas generales, apunta a identificar buenos y malos. La acción en perjuicio de la Patria por parte de éstos últimos, habilitaría al gobierno a tomar las medidas que considere necesarias con el objetivo de frenar la acción destructora. Lo que no siempre queda plasmado explícitamente, son los medios que empleará para tal fin. En algunos casos, será la justicia quien determine el castigo, pero en otros subyace la idea de una represión armada.

Los indecisos o paradestinatarios son interpelados con el fin de unirse a las filas del gobierno, se los busca cooptar. Dichos destinatarios son llamados a ocupar el lugar que les corresponde en la lucha contra la violencia a través de una toma de posición en términos de: "están con nosotros o contra nosotros". Hábilmente Isabel no deja lugar a otra alternativa posible, se puede estar del lado del bien o del caos.

Más allá de la efectividad o el fracaso de las estrategias discursivas empleadas por Isabel para legitimarse en el cargo presidencial -cuya validez no nos compete determinar-, no podemos negar que las mismas mantuvieron cierta coherencia en relación a las palabras pronunciadas y el auditorio que las recibía. El endurecimiento de su postura y su discurso se hizo evidente en momentos de profunda crisis o con el objetivo de hacer frente a sus opositores en distintos ámbitos. Quienes aun no presentaban una postura clara respecto al gobierno, los llamados indecisos, buscaron ser atraídos a las filas oficiales.

Como hemos señalado con anterioridad en este trabajo, el gobierno de Isabel se vio abruptamente finalizado por un golpe de estado cívico-militar. No intentamos atribuir su revés político como presidente a la falta de eficacia de las mencionadas estrategias ya que éstas por sí mismas no determinan el éxito o el desplome de un gobierno.

\section{Fuentes primarias de información}

María Estela Martínez de Perón (1974a) "Las veinte verdades del justicialismo", Presidencia de la Nación. Secretaría de Prensa y Difusión. Buenos Aires. 
María Estela Martínez de Perón (1974b) "Mensaje a los trabajadores del mundo, la vicepresidente María Estela Martínez de Perón, habla en la 59 reunión de la OIT", Presidencia de la Nación. Secretaría de Prensa y Difusión, Buenos Aires, julio.

María Estela Martínez de Perón (1974c) "La señora vicepresidente habla sobre el desabastecimiento", Presidencia de la Nación. Secretaría de Prensa y Difusión. Buenos Aires, 10 de junio.

María Estela Martínez de Perón (1974d) "La Presidente de la Nación, inaugura la Conferencia interamericana sobre planificación de seguridad social", Presidencia de la Nación. Secretaría de Prensa y Difusión. Buenos Aires, 29 de julio.

María Estela Martínez de Perón (1974e) "Discursos y mensajes de la presidente de la Nación María Estela Martínez de Perón", Presidencia de la Nación. Secretaría de Prensa y Difusión. Buenos Aires, 8 de julio a 12 de septiembre.

María Estela Martínez de Perón (1974f) "El país contra la violencia. Discurso pronunciado por la presidente de la Nación María Estela Martínez de Perón en la Asamblea Multisectorial". Presidencia de la Nación. Secretaría de Prensa y Difusión. Buenos Aires, 8 de octubre.

Diario La Nueva Provincia, "Visita el interior la jefa de estado" Bahía Blanca, 13 de octubre de 1974, p 3, cols 3-6, continuación p 5, col 1.

Diario La Nueva Provincia, "Nuevo mensaje presidencial", Bahía Blanca, 14 de octubre de 1974, p 4, cols 1-4.

María Estela Martínez de Perón (1975a) "1 de mayo de 1975. Discurso de la excelentísima Sra. Presidente de la Nación Doña María Estela Martínez de Perón desde el Congreso Nacional y mensaje al pueblo desde el balcón de la Casa de Gobierno", Presidencia de la Nación. Secretaría de Prensa y Difusión. Buenos Aires, 1 de mayo.

María Estela Martínez de Perón (1975b) "Discurso pronunciado por la Excma. Sra. Presidente de la Nación, doña María Estela Martínez de Perón, desde el balcón histórico de la Casa de Gobierno, con motivo de la celebración del Día de la Lealtad", Presidencia de la Nación. Secretaría de Prensa y Difusión. Buenos Aires, 17 de octubre.

María Estela Martínez de Perón (1976a) "Discurso de Isabel Perón en el Teatro Colón el 1 de enero de 1976 con motivo de la entrega de sables y espadas a los nuevos oficiales de las FF.AA", Diario La Nación 10 de enero, en Itcovitz Victoria "Estilo de gobierno y crisis política (1973-1976)", Centro editor de América Latina, Buenos Aires, 1985.

María Estela Martínez de Perón (1976b) Presentación del Decreto № 906 que establece la puesta en marcha de la "Comisión Especial de las Remuneraciones, la Productividad y la Participación" en el ámbito de competencia de los Ministerios de Economía y de Trabajo. Discurso del Secretario General de la CGT, Casildo Herrera; lectura del Decreto y discurso de la Presidenta María Estela Martínez de Perón. Emisión radial RTA Buenos Aires, 10 de marzo. Disponible en: https://www.youtube.com/watch?v=UjX6dctP7rA , consultado el 12 de junio 2016. 


\section{Referencias bibliográficas}

Anzorena, O. (1998). Tiempo de violencia y utopía, del golpe de Onganía (1966) al golpe de Videla (1976). Buenos Aires: Ediciones del Pensamiento Nacional.

Arfurch, L. (1987). Dos variantes del juego de la política en el discurso electoral de 1983. En

AA.VV. El discurso político. Lenguajes y acontecimientos. Buenos Aires: Hachette.

De Riz, L. (1981). Retorno y derrumbe. El último gobierno peronista. Buenos Aires: Folios.

dos Santos, E. (1983). Las mujeres peronistas. Buenos Aires: Centro editor de América Latina.

Feinmann, J. P. (2011). Peronismo. Filosofía política de una persistencia Argentina (Vol. 2). Buenos Aires: Planeta.

Fraga, R. (1988). Ejército: del escarnio al poder (1973-1976). Buenos Aires: Sudamericana/Planeta.

Franco, M. (2012). Un enemigo para la Nación. Orden interno, violencia y “subversión", 19731976. Buenos Aires: Fondo de Cultura Económica.

Gabini, H. (2008). Historia del Peronismo III. La violencia (1956-1983). Buenos Aires: Planeta.

Golman, N. (1989). El discurso como objeto de la historia. Buenos Aires: Hachette.

González, J. (2007). Isabel Perón, intimidades de un gobierno. Buenos Aires: Editorial El Ateneo.

Halperin, J. (2009). Las muchachas peronistas: Eva, Isabel y Cristina. Buenos Aires: Aguilar. Horowicz, A. (1986) Los cuatro peronismos, Buenos Aires: Hyspamérica.

Itcovitz, V. (1985). Estilo de gobierno y crisis politica (1973-1976). Buenos Aires: Centro editor de América Latina.

Kandel, P. y Monteverde, M. (1976). Entorno y caída. Buenos Aires: Ed. Planeta.

Larraquy, M. (2007). López Rega, el peronismo y la Triple A. Buenos Aires: Punto de lectura. Martín Rojo, L. (1997). El orden social de los discursos. Discurso 21/22 (pp. 1-37). México.

Roffinelli, G. y Artese, M. (2007). Responsabilidad civil y genocidio. Tucumán en años del 'Operativo Independencia' (1975-76). Buenos Aires: Tientos Editora. Recuperado (29/09/2016)

en:

http://webiigg.sociales.uba.ar/conflictosocial/libros/artese/respcivil genocidio.pdf

Sáenz Quesada, M. (2003). Isabel Perón, la Argentina en los años de María Estela Martínez. Buenos Aires: Editorial Planeta.

Scandell Vidal, M. V. (1996). Introducción a la Pragmática. Barcelona: Ariel.

Servetto, A. (2010). 73/76. El gobierno peronista contra las "provincias montoneras". Buenos Aires: Siglo XXI.

Servetto A. M. y Paiaro, M. (2012). Las palabras del terror. Los discursos de la presidenta María Estela Martínez de Perón y su legitimación de los dispositivos de la violencia 
estatal y paraestatal, en Passagens. Revista Internacional de História Política e Cultura Jurídica, Río de Janeiro, 4 (2), 193-212. Recuperado (14/09/2015) en: http://dialnet.unirioja.es/servlet/articulo?codigo $=3915148$

Sidicaro, R. (2002). Los tres peronismos: estado y poder económico, 1946-55/1973-76/198999. Buenos Aires: Siglo Veintiuno.

Sigal S. y Verón E. (1988). Perón o muerte, los fundamentos discursivos del fenómeno peronista. Buenos Aires: Hyspamerica.

Verón, E. et al. (1987). El discurso político: lenguajes y acontecimientos. Buenos Aires: Hachette.

Wodak, R. y Meyer, M. (2003). Métodos de Análisis Crítico del Discurso. Barcelona: Gedisa.

Yofre, J. B. (2010). "Nadie fue”: crónica de los últimos meses días y horas de Isabel Perón en el poder. Buenos Aires: Ed. Sudamericana.

Yoris-Villasana, C. (2004). 18 de octubre de 1945: legitimidad y ruptura del hilo constitucional. Caracas: Biblioteca de la Academia Nacional de Historia, Estudios, Monografías y Ensayos. 